\title{
POLÍTICAS PÚBLICAS COMO EFETIVAÇÃO DA TUTELA CONSTITUCIONAL DO
}

\author{
DIREITO À EDUCAÇÃO
}

\author{
Clovis Demarchi ${ }^{1}$ \\ https://orcid.org/0000-0003-0853-0818 \\ Jeane Cristina de Oliveira Cardoso ${ }^{2}$ \\ https://orcid.org/0000-0001-5352-0905
}

Recebido em: 9 jul. 2020

Aceito em: 18 out. 2020

\begin{abstract}
Como citar este artigo: Clovis Demarchi; CARDOSO, Jeane Cristina de Oliveira. POLÍTICAS PÚBLICAS COMO EFETIVAÇÃO DA TUTELA CONSTITUCIONAL DO DIREITO À

EDUCAÇÃO. Revista Visão: Gestão Organizacional, Caçador, SC, Brasil, v. 9, n. 2, p. 87-101, jul./dez. 2020. Disponível em: http://dx.doi.org/10.33362/visao.v9i2.2431.
\end{abstract}

Resumo: Este artigo aborda aspectos do Direito à Educação preceituado no ordenamento jurídico brasileiro, especialmente, no tratamento consagrado na norma constitucional, disposto na CRFB/1988, sobretudo na importância atribuída ao tema caracterizando-o como um Direito Social, de grande relevância para a Sociedade e Estado. Procura-se demonstrar a superioridade das normas constitucionais em relação às demais normas do ordenamento jurídico e a abordagem do texto constitucional acerca da Educação. A Educação por ser o direito que contribui para o crescimento intelectual, social e cultural do indivíduo, foi alçada ao nível de norma constitucional. Sua importância é de tamanha relevância que foi caracterizada como direito social e apresenta uma seção específica dos artigos 205 ao 214. O direito a educação, encontra guarida nas ações do Estado, nos três níveis (união, estado e municípios) através de Políticas Públicas criadas com a intenção de fortalecer esse direito.

Palavras-Chave: Norma Constitucional. Direito à Educação. Políticas Públicas

PUBLIC POLICIES AS EFFECTIVENESS OF THE CONSTITUTIONAL PROTECCION TO THE RIGHT TO EDUCATION

Abstract: This article addresses aspects of the Right to Education prescribed in the Brazilian legal system, especially in the treatment enshrined in the constitutional rule, provided for in Constitution of 1988, above all in the importance attributed to the theme, characterizing it as a Social Law, of great relevance to Society and State. It seeks to demonstrate the superiority of the constitutional rules in relation to the other norms of the legal system and the approach of the constitutional text about Education. Education, being the right that contributes to the individual's intellectual, social and cultural growth,

\footnotetext{
${ }^{1}$ Doutor em Ciência Jurídica pela Universidade do Vale do Itajaí. Doutorado Sanduíche com a Universidade do Minho, Braga - Portugal com Bolsa CAPES. Mestre em Ciência Jurídica pela Universidade do Vale do Itajaí. É professor titular da Universidade do Vale do Itajaí nos cursos de graduação, especialização e no Programa de PósGraduação "Stricto sensu" em Ciência Jurídica. E-mail: demarchi@univali.br.

2 Doutoranda e Mestre em Ciência Jurídica pela Universidade do Vale do Itajaí. Coordenadora de Educação a Distância da UNIVALI/SC e Procuradora Educacional Institucional (PI) da UNIVALI/SC. E-mail: jeane@univali.br.
} 
was raised to the level of constitutional norm. Its importance is of such relevance that it was characterized as a social right and presents a specific section of articles 205 to 214. The right to education, finds shelter in the actions of the State, at the three levels (union, state and municipalities) through Public Policies created with the intention of strengthening this right.

Keywords: Constitutional Norm. Right to education. Public policy

\section{INTRODUÇÃO}

A Educação figura como uma das invocações da Sociedade no sentido de corroborar para o desenvolvimento da pessoa humana e, consequentemente, de uma Nação. A Educação contribui para o crescimento intelectual, social e cultural do indivíduo.

Por esta razão, alcançou o nível mais elevado de uma norma do ordenamento jurídico brasileiro, ou seja, o de norma constitucional. Sua importância é de tamanha relevância que a Constituição da República Federativa do Brasil de 1988 (CRFB/1988) caracterizou-a como um direito social no intuito de proteger a estruturação do Bem Comum de uma Sociedade.

Com a caracterização como direito social (artigo 6ㅇ) mais uma seção específica (art. 205 ao 214) (BRASIL, 2019). Desta forma, é reconhecido o papel que a CRFB/1988 representa na consolidação da normatividade e das garantias de aplicabilidade da Educação, demonstrando o compromisso do Estado com o desenvolvimento da Sociedade.

Este estudo tem por objeto o Direito à Educação no ordenamento jurídico brasileiro, especialmente, no tratamento consagrado na norma constitucional, disposto na CRFB/1988, sobretudo na importância atribuída ao tema caracterizando-o como um Direito Social.

Nesta perspectiva, objetiva-se demonstrar a superioridade da norma constitucional no ordenamento jurídico brasileiro e identificar a dimensão proposta para este tema na CRFB/1988 evidenciando a responsabilidade do Estado em assegurar a aplicabilidade da norma disposta da Constituição.

$\mathrm{O}$ artigo está dividido em quatro momentos. No primeiro se verifica a supremacia da norma constitucional no ordenamento jurídico brasileiro. No segundo trata-se da educação no contexto da constituição de 1988. O terceiro trata do dever do Estado com a educação e finalmente se apresenta algumas políticas públicas na área da educação que representam a preocupação dos entes federados com a concretização do direito à educação.

Utilizar-se-á o método indutivo com a pesquisa bibliográfica e documental.

Destaca-se que Educação é entendida conforme a Lei de Diretrizes e Bases (BRASIL, 1996) ou seja, "[...] os processos formativos que se desenvolvem na vida familiar, na convivência humana, no trabalho, nas instituições de ensino e pesquisa, nos movimentos sociais e organizações da sociedade civil e nas manifestações culturais". A partir desta ideia de educação é possível vislumbrar o desenvolvimento social, econômico e cultural do indivíduo a 
partir da Educação.

Para o entendimento de direito, utilizou-se como referência Kelsen (1998, p. 21) ao afirmar que direito é "Uma "ordem" e um sistema de normas cuja unidade é constituída pelo fato de todas elas terem o mesmo fundamento de validade". Assim, conforme Kelsen, as normas de uma ordem jurídica regulam a conduta humana. Desta forma, o Direito é considerado a norma que regula as ações das pessoas na vida em Sociedade, isto é, são regras que garantem a convivência social.

Comungando com a ideia de Kelsen, se terá como parâmetro também a ideia de Bobbio (1995, p. 25), ao entender direito como "[...] conjunto de regras que se fazem valer ainda que pela força, isto é, um ordenamento normativo de eficácia reforçada [...]".

Entender-se-á direito fundamental como aquele básico ao indivíduo que conforme Silva $(2005$, p. 178) refere-se a "princípios que resumem a concepção do mundo e informam a ideologia política de cada ordenamento jurídico". Neste sentido, a expressão "Direitos Fundamentais" destina a natureza de direito que tutela a dignidade, a igualdade e a liberdade da pessoa humana. A CRFB/1988 classifica os Direitos Fundamentais em cinco grupos, dentre eles, os direitos sociais, onde reside o Direito à Educação, assinalado por Silva (2005. p. 286) como "[...] prestações positivas proporcionadas pelo Estado direta ou indiretamente, [...] que possibilitam melhores condições de vida aos mais fracos, direitos que tendem a realizar a igualização de situações sociais desiguais".

\section{A SUPREMACIA DA NORMA CONSTITUCIONAL}

O Direito Constitucional, ramo do Direito Público, tem sua peculiaridade pela natureza e objeto que o formam, além de reunir em seu conteúdo normas e preceitos da mais elevada hierarquia em relação as demais normas de um Estado.

Como preceitua Silva (2005, p. 34), "podemos defini-lo como o ramo do Direito Público que expõe, interpreta e sistematiza os princípios e normas fundamentais do Estado", o Autor entende que o Direito Constitucional é a ciência positiva das constituições.

O Direito Constitucional positivo reúne normas jurídicas denominadas normas constitucionais que instituem o Estado e que regem a Sociedade. Pode ser caracterizado pelo poder de ação fundado na norma, objetivando a tutela de bem ou interesse próprio. As normas constitucionais são regras e princípios expressos na Constituição e/ou regras da vida social e, por assim serem, são dotadas de máxima hierarquia, que devem ser observadas propagando uma dimensão subjetiva do Direito Constitucional.

Assim, o direito constitucional, segundo Barroso (2015, p. 73) consiste não somente no texto original da constituição editada pelos constituintes originários, mas também " [...] o que for acrescentado por emendas constitucionais, quer figurem diretamente no texto, quer 
tenham uma existência autônoma, a ele justaposta".

A ascensão científica e institucional do Direito Constitucional, explica Barroso (2015, p. 73), foi expressa pela conquista da normatividade e peculiaridades evidenciadas pelos múltiplos critérios de classificação, pelos princípios e regras de organização de conduta da Sociedade.

Nesta acepção, a Constituição é o instrumento que reúne e sistematiza o conjunto de normas constitucionais, materializado em um documento escrito que define a organização do poder político de um Estado. "Lei suprema do Estado, [...] nela que se acham as normas fundamentais de Estado, e nisso se notará sua superioridade em relação às demais normais jurídicas. (SILVA, 2005, p. 45)

A Constituição é a mais elevada expressão jurídica de um Estado, nesta linha Barroso (2015, p. 74 ) ensina que as "[...] normas constitucionais tutelam bens jurídicos socialmente relevantes e interesses individuais", assim, as normas constitucionais definem a organização e todos os princípios e regras fundamentais, consideradas essenciais na estruturação e organização de um Estado. Assim, "[...] um direito subjetivo constitucional confere a seu titular a faculdade de invocar a norma da Constituição para assegurar o desfrute da situação jurídica nela contemplada".

Neste entendimento pode-se afirmar que toda norma inserida no corpo de uma Constituição está revestida de força jurídica superior e desfruta de posicionamento especial em relação a qualquer outra norma do ordenamento jurídico.

A superioridade das normas constitucionais fundamenta-se na relação entre as normas que regulam a produção e as normas produzidas, para tanto, preconiza Kelsen (1998, p.155) “A norma que regula a produção é a norma superior, a norma produzida [...] daquela é a norma inferior. [...] A norma fundamental [...] é, portanto, o fundamento de validade último que constitui a unidade desta interconexão criadora".

Contudo, a Constituição representa o conjunto de normas da mais elevada hierarquia no ordenamento jurídico de um Estado, normas constitucionais que regulam a criação das demais normas jurídicas de uma Nação, que Ihe conferem a superioridade hierárquica, a supremacia pelo seu caráter de Lei Maior. No mesmo entendimento Kelsen (1998, p.166) ensina que, "a Constituição representa o escalão de Direito positivo mais elevado".

A separação de Poderes e a garantia dos direitos é a essência da Constituição, desde as suas origens, assim, o "constitucionalismo surge como uma doutrina de limitação do poder do Estado", considerando a ampliação do elenco de direitos tidos como fundamentais, incluindo, além dos direitos políticos e individuais, os direitos sociais e coletivos (BARROSO, 2015, p.107).

Entretanto, é possível afirmar que a vigência de uma norma, por sua mera existência, não expressa a sua realizabilidade, nem mesmo a imperatividade peculiar das normas 
constitucionais. É necessário, para além da existência de uma norma constitucional, a adesão de seus destinatários e a atuação do Estado no exercício regular de sua função.

Assim, não basta a existência de uma norma constitucional e sua supremacia, é necessário garantir e a proteger os preceitos dispostos na Constituição, bem como, mecanismos de fomento destas garantias. Neste cenário, é importante destacar o protagonismo do Estado para efetivação das normas constitucionais.

\section{A EDUCAÇÃO NA CONSTITUIÇÃO BRASILEIRA DE 1988}

A CRFB/1988 (BRASIL, 2019) constitui a base da organização educacional brasileira como norma constitucional e classifica a Educação como um Direito Social, nos termos do art. 6o: "São direitos sociais a educação, a saúde, a alimentação, o trabalho, a moradia, o transporte, o lazer, a segurança, a previdência social, a proteção à maternidade e à infância, a assistência aos desamparados, na forma desta Constituição".

Na norma constitucional, a Educação está posta como um Direito Social elevada ao mesmo patamar da saúde, da alimentação, do trabalho, da moradia, dentre outros previstos no art. 6ㅇ․ É importante destacar que os Direitos Sociais estão no rol dos Direitos e Garantias Fundamentais da Constituição, portanto, a Educação é Direito Fundamental imposto pela Constituição ao Estado. Conforme Demarchi e Coelho (2018, p. 192) o Direito à Educação assegurado a todos os brasileiros, constitui requisito para a efetivação do Estado Constitucional de Direito que tem como fundamentos a 'cidadania' e 'a dignidade da pessoa humana'

A narrativa constitucional na qual se insere a Educação deve ser interpretada a partir do pressuposto de sua acentuada relação com os demais Direitos Sociais previstos no art. 6o , submetendo-se ao conceito de norma constitucional e de sua supremacia, bem como, a de Direito Fundamental.

Não obstante, no Título da Ordem Social, a partir do art. 205, em seção própria, a educação se apresenta como um direito de todos e dever do Estado: "A educação, direito de todos e dever do Estado e da família, será promovida e incentivada com a colaboração da sociedade, visando ao pleno desenvolvimento da pessoa, seu preparo para o exercício da cidadania e sua qualificação para o trabalho" (BRASIL, 2019).

O dever com a Educação é estendido a família e envolve a colaboração da Sociedade, dado que o processo educacional é considerado um elemento de desenvolvimento e de formação da pessoa humana que abrange aspectos essenciais da vida em Sociedade. Entretanto, ao considerar os princípios ordenados no art. 206, a Educação é um Direito Público obrigatório e gratuito, devendo ser ministrado em igualdade de condições tanto para o acesso quanto à permanência.

Art. 206. O ensino será ministrado com base nos seguintes princípios: 
I - Igualdade de condições para o acesso e permanência na escola;

II - Liberdade de aprender, ensinar, pesquisar e divulgar o pensamento, a arte e o saber;

III - pluralismo de idéias e de concepções pedagógicas, e coexistência de instituições públicas e privadas de ensino;

IV - Gratuidade do ensino público em estabelecimentos oficiais;

V - Valorização dos profissionais da educação escolar, garantidos, na forma da lei, planos de carreira, com ingresso exclusivamente por concurso público de provas e títulos, aos das redes públicas;

VI - Gestão democrática do ensino público, na forma da lei;

VII - garantia de padrão de qualidade.

VIII - piso salarial profissional nacional para os profissionais da educação escolar pública, nos termos de lei federal.

Parágrafo único. A lei disporá sobre as categorias de trabalhadores considerados profissionais da educação básica e sobre a fixação de prazo para a elaboração ou adequação de seus planos de carreira, no âmbito da União, dos Estados, do Distrito Federal e dos Municípios. (BRASIL, 2019)

A expressão "permanência" disposta na norma constitucional pode ser interpretada como a efetivação da Educação como um Direito Social, uma vez que não basta promover o acesso à Educação por meio da escola, é preciso garantir a permanência do indivíduo e sua continuidade neste meio durante o período necessário à formação projetada no ordenamento jurídico.

Outro ponto que cabe destacar é o direito ao ensino de qualidade. A garantia de padrão de qualidade associada a gratuidade do ensino público é de extrema relevância, entretanto, são garantias que merecem ênfase em razão da realidade social que se manifesta na Sociedade contemporânea.

O disposto no art. 207 da CRFB/1988 (BRASIL, 2019) é destinado ao ensino superior, entretanto, cabe destacar o cuidado e a preocupação do legislador com a associação do ensino, pesquisa e extensão, fato que salienta a característica da Educação como Direito Social.

Art. 207. As universidades gozam de autonomia didático-científica, administrativa e de gestão financeira e patrimonial, e obedecerão ao princípio de indissociabilidade entre ensino, pesquisa e extensão.

$\S 1$ 으 É facultado às universidades admitir professores, técnicos e cientistas estrangeiros, na forma da lei.

$\S 2$ ○ O disposto neste artigo aplica-se às instituições de pesquisa científica e tecnológica.

O art. 208 da CRFB/1988 descreve os deveres do Estado com a Educação, cabendo ressaltar que este dever perpassa todos os níveis de ensino previsto no ordenamento jurídico, da educação básica a superior. Não obstante, a norma prevê como dever peculiaridades e especificidades, tais como, a inserção das pessoas com deficiência e a oferta em turno noturno para aqueles que estão impossibilitados de estudar durante o dia.

Art. 208. O dever do Estado com a educação será efetivado mediante a garantia de:

I - Educação básica obrigatória e gratuita dos 4 (quatro) aos 17 (dezessete) anos de 
idade, assegurada inclusive sua oferta gratuita para todos os que a ela não tiveram acesso na idade própria;

II - Progressiva universalização do ensino médio gratuito;

III - atendimento educacional especializado aos portadores de deficiência, preferencialmente na rede regular de ensino;

IV - Educação infantil, em creche e pré-escola, às crianças até 5 (cinco) anos de idade;

$\checkmark$ - Acesso aos níveis mais elevados do ensino, da pesquisa e da criação artística, segundo a capacidade de cada um;

VI - oferta de ensino noturno regular, adequado às condições do educando;

VII - atendimento ao educando, em todas as etapas da educação básica, por meio de programas suplementares de material didático escolar, transporte, alimentação e assistência à saúde.

$\S 1$ 응 $\mathrm{O}$ acesso ao ensino obrigatório e gratuito é direito público subjetivo.

§ 2 o O não-oferecimento do ensino obrigatório pelo Poder Público, ou sua oferta irregular, importa responsabilidade da autoridade competente.

$\S 3$ ㅇ Compete ao Poder Público recensear os educandos no ensino fundamental, fazer-Ihes a chamada e zelar, junto aos pais ou responsáveis, pela frequência à escola. (BRASIL, 2019)

O inciso VII do art. 208 prescreve como dever o fomento de programas suplementares para suprir necessidades adjacentes ao acesso, tais como, transporte e alimentação visando a elevação da permanência.

A extensão da oferta do ensino à iniciativa privada prescrita no art. 209 não desobriga o Estado, além de que, é dever deste a responsabilidade por autorizar e avaliar permanentemente esta oferta.

Art. 209. O ensino é livre à iniciativa privada, atendidas as seguintes condições:

I - Cumprimento das normas gerais da educação nacional;

II - Autorização e avaliação de qualidade pelo Poder Público.

O art. 210 delineia os conteúdos mínimos para o ensino fundamental visando assegurar e respeitar os valores culturais e artísticos de acordo com os costumes e os fundamentos da diversidade de comunidades distribuídas no território brasileiro, manifestando os princípios dispostos no art. 206.

Art. 210. Serão fixados conteúdos mínimos para o ensino fundamental, de maneira a assegurar formação básica comum e respeito aos valores culturais e artísticos, nacionais e regionais.

$\S 1$ O O ensino religioso, de matrícula facultativa, constituirá disciplina dos horários normais das escolas públicas de ensino fundamental.

$\S 2$ ○ O ensino fundamental regular será ministrado em língua portuguesa, assegurada às comunidades indígenas também a utilização de suas línguas maternas e processos próprios de aprendizagem.

Os artigos 211 a 214 da CRFB/1988 estabelecem os papeis e as responsabilidades dos entes federativos do Estado (União, Estados, Distrito Federal e Municípios) determinando o regime de colaboração entre eles, entretanto, cabe destacar que à União caberá o cuidado com a qualidade do ensino, além da obrigação de dispensar todo o apoio aos demais entes 
federativos. Os Municípios devem atuar prioritariamente no ensino fundamental e na educação infantil e os Estados e Distrito Federal tem o dever com o ensino fundamental e médio. Neste contexto, a norma constitucional determina a necessária articulação entre a União, Estados, Distrito Federal e Municípios com vistas a efetivação do disposto na norma como dever do Estado (BRASIL, 2019).

Esta divisão de competências e distribuição de responsabilidades impostas pela CRFB/1988 aos entes federativos demonstra uma preocupação do legislador e, por conseguinte, uma forma de minimizar a omissão e intimar o Estado no seu dever de fazer o que prevê a norma.

O art. 212 expressa um compromisso em guarnecer o dever do Estado com a educação ao disciplinar a destinação de determinados impostos para o custeio do direito à educação, bem como, à manutenção e desenvolvimento desta. Estes são meios que intentam na efetivação do direito à educação, entretanto, considerando a extensão da oferta do ensino à iniciativa privada, o disposto no art. 213 prevê a possibilidade de ajuda financeira do governo à entidades educacionais sem fins lucrativos, bem como, as atividades de pesquisa e extensão desenvolvidas nas universidades (BRASIL, 2019).

É importante observar que o texto do art. 214 refere-se ao plano nacional de educação e que a própria norma já concebe o escopo deste documento ao apresentar os objetivos que devem ser perseguidos e inseridos nele:

Art. 214. A lei estabelecerá o plano nacional de educação, de duração decenal, com o objetivo de articular o sistema nacional de educação em regime de colaboração e definir diretrizes, objetivos, metas e estratégias de implementação para assegurar a manutenção e desenvolvimento do ensino em seus diversos níveis, etapas e modalidades por meio de ações integradas dos poderes públicos das diferentes esferas federativas que conduzam a:

I - erradicação do analfabetismo;

II - universalização do atendimento escolar;

III - melhoria da qualidade do ensino;

IV - formação para o trabalho;

$\checkmark$ - promoção humanística, científica e tecnológica do País.

VI - estabelecimento de meta de aplicação de recursos públicos em educação como proporção do produto interno bruto (BRASIL, 2019).

Por fim, a CRFB/1988 dedica alguns de seus artigos à Educação e expressa sua natureza de Direito Social, traçando o caminho e orientando a Sociedade deste direito. Destarte, o Direito à Educação é norma constitucional dotada de supremacia, contudo, a norma por si só não garante este direito e não é capaz de modificar a realidade social, a garantia de efetivação deste direito é dever do Estado. 


\section{EDUCAÇÃO E O DEVER DO ESTADO}

A partir da CRFB/1988 tem-se a Educação como um Direito Fundamental Social, desta forma, fica subentendido que o Estado por meio dos entes da federação e dos poderes executivo, legislativo e judiciário tem o dever de efetivar os direitos e garantias constitucionais, seja em âmbito de promover ou fiscalizar este direito.

Silva (2005, p. 189) prescreve que o conjunto de garantias dos Direitos Fundamentais prescritos na CRFB/1988 forma o sistema de proteção social, política e jurídica

Considerando a Teoria do Estado proposta por Heller (1968, p. 232-233), destaca-se que "a vontade do Estado é a que cria e assegura o direito positivo" e, esta vontade não poderá ser livre de normas, tampouco de obrigações que por sua vez podem ser variáveis de acordo com o meio social que o estabelecem. Neste sentido, "o direito é a forma de manifestação eticamente necessária do Estado. A vontade deste deve ser concebida como uma indubitável realidade social existencial".

Sobretudo, "o 'poder' do Estado deve ser a validade e a eficácia da ordem jurídica nacional", neste sentido, Kelsen (1998, p. 364-365) prescreve que "o poder é compreendido como uma função do Estado".

No entendimento de Heller (1968, p. 289), o poder do Estado é difundido de forma que todos participam, no entanto, este poder é o resultado de ações consideradas politicamente relevantes. Sob a ótica política, o Estado é uma conexão real de efetividades, não uma simples soma de forças particulares, mas, o resultado da cooperação entre a Sociedade e os governantes. Segundo o Autor, a Constituição de um Estado compatibiliza com sua organização, considerando que esta é produzida mediante atividade humana consciente de todos.

Desta forma o Estado, "o Estado existe para realizar a Justiça, condição primeira do bem-estar do indivíduo e da sociedade" (GOULART, 1995, p.19), assim, em razão de sua função social, o Estado deve promover alternativas que podem ser adotadas com o objetivo de promover a eficácia das normas jurídicas constitucionais.

Nesse contexto Pasold (2013, p. 44-50) preceitua que "O Poder do Estado Contemporâneo é soberano especialmente porque tem a capacidade de atribuir ao seu ordenamento jurídico uma validade", característica distintiva a outras ordenações sociais. Nas palavras do autor, o Estado deve ter uma "Função Essencial" que nasce da relação peculiar entre a Sociedade e o Estado e, sendo assim, "é necessário colocar o Estado de forma permanente e pró ativa em função de toda a Sociedade".

Considerando que o poder do Estado é aquele capaz de preservar direitos e deveres a serviço da Sociedade, é necessário que "[...] exerça uma Função Social [...] privilegiando os Valores fundamentais do Ser Humano" (PASOLD, 2013, p. 52). 
A efetivação dos direitos e garantias fundamentais prescritos na CRFB/1988 devem ser perseguidas pelo Estado, considerando sua investidura de poder e autoridade para impor o cumprimento do ordenamento constitucional. Desta forma a Função Social do Estado é de agir em prol da Sociedade e do Todo Social "[...] o agente é o Estado - cuja natureza deve ser a de criatura da Sociedade e, portanto, instrumento a serviço do Todo Social". (PASOLD, 2013, p. 61)

Neste universo, o Estado deve comprometer-se com a implantação de ações que promovam a eficácia da Educação como um Direito Fundamental Social, conforme disposto na norma constitucional.

Diante do exposto, cabe destacar que a garantia e a efetivação do Direito a Educação não podem ser prejudicadas por inércia dos órgãos investidos de poder e autoridade para este fim, de outro modo, "o Estado pode, contudo, ser obrigado a reparar o dano que consiste em não-cumprimento de sua obrigação" (KELSEN, 1998, p. 287).

O poder do Estado se estende a ação obrigatória do Estado como ente federativo instituído para portar-se diante da Sociedade como agente na esteira da efetivação do interesse coletivo.

\section{POLÍTICAS PÚBLICAS DE EDUCAÇÃO E DEVER DO ESTADO}

Há várias Políticas públicas que foram pensadas, criadas e efetivadas visando a concretização do direito social à educação como forma de o Estado efetivar este direito.

Neste momento serão destacadas três delas. Relembrando que a apresentação visa demonstrar que existem possibilidades de efetivar os direitos sociais, não cabendo a este momento analisar se elas resultaram nos objetivos pretendidos, mas relatar a experiência de forma breve.

\section{FUNDO DE MANUTENÇÃO E DESENVOLVIMENTO DA EDUCAÇÃO BÁSICA}

O Fundo de Manutenção e Desenvolvimento da Educação Básica e de Valorização dos Profissionais da Educação - FUNDEB é um Fundo instituído pela Emenda Constitucional n. 53, de 19 de dezembro de 2006 (BRASIL, 2019), regulamentada pela Medida Provisória 339, de 28 de dezembro do mesmo ano e convertida na Lei no 11.494 de 20 de junho de 2007 (BRASIL, 2007a).

A vigência do FUNDEB se deu a partir de 10 de janeiro de 2007. A implantação se dará progressivamente em três anos, conforme artigo $31^{3}$ da lei 11.494 , atingindo sua plenitude em

\footnotetext{
3 “Art. 31. Os Fundos serão implantados progressivamente nos primeiros 3 (três) anos de vigência, conforme o disposto neste artigo".
} 
2009. Em 2009, o fundo deveria estar atendendo todo o universo de alunos da educação básica presencial, bem como os percentuais de receita teriam que ter alcançado o limite de $20 \%$ de contribuição conforme art. 3ํํำ da lei 11.494 .

Importante ressaltar que desde a Constituição de 1988, 25\% da receita dos impostos e transferências dos Estrados, Distrito Federal e Municípios se encontram vinculados à educação. Bem como é interessante lembrar que a Emenda Constitucional n. 14/96, estipulou que $60 \%$ desses recursos da educação passariam a ser sub-vinculados ao Ensino Fundamental, ou seja, $15 \%$ dos impostos e transferências. Essa partilha de recursos entre o Governo Estadual e seus municípios, tinha como base o número de alunos do ensino fundamental atendidos em cada rede de ensino, daí o Fundo de Manutenção e Desenvolvimento do Ensino Fundamental e de Valorização do Magistério - FUNDEF.

A Emenda Constitucional n. 53/2006, fez uma profunda alteração nesse Fundo ao subvincular as receitas dos impostos e transferências dos Estados, Distrito Federal e Municípios para $20 \%$ e sua utilização ampliada para toda a Educação Básica, daí FUNDEF, que também faz distribuição dos recursos com base no número de alunos, não mais somente do Ensino Fundamental, mas Educação Básica pública, ou seja: Educação Infantil, Educação Fundamental e Ensino Médio.

O FUNDEF foi implantado a partir de 1997 com vigência de 10 anos, encerrando-se em 31 de dezembro de 2006. O FUNDEB terá vigência de 14 anos, de 1o de janeiro de 2007 até 31 de dezembro de 2020 conforme art. $48^{5}$ da lei 11.494 .

\section{PROGRAMA UNIVERSIDADE PARA TODOS}

O Programa Universidade para Todos - PROUNI, regula a atuação de entidades beneficentes de assistência social no ensino superior; altera as Leis no 10.891 de 09 de julho de 2004; e dá outras providências. O programa foi criado a partir da Medida Provisória 213/2004. A medida provisória foi transformada na lei n.o 11.096 em 13 de janeiro de 2005. (BRASIL, 2005a). A lei foi regulamentada através do decreto n. 5.493 de 18 de julho de 2005 (BRASIL, 2005 b).

Segundo o artigo 1으 do decreto, o Programa Universidade para Todos - PROUNI, destina-se à concessão de bolsas de estudo integrais e bolsas de estudo parciais de cinquenta por cento ou de vinte e cinco por cento, para estudantes de cursos de graduação ou sequenciais de formação específica, em instituições privadas de ensino superior, com ou sem fins lucrativos, que tenham aderido ao PROUNI nos termos da legislação aplicável.

\footnotetext{
4 "Art. 3o Os Fundos, no âmbito de cada Estado e do Distrito Federal, são compostos por 20\% (vinte por cento) das seguintes fontes de receita [...]".

5 “Art. 48. Os Fundos terão vigência até 31 de dezembro de 2020".
} 
O Programa vem de encontro ao proposto pelo artigo 150, inciso VI, alínea C e no artigo 195 § 7 da Constituição da República Federativa do Brasil de 1988 (BRASIL, 2019), que exige que as instituições de Ensino Superior sem fins lucrativos realizem sua contrapartida por serem isentas do pagamento de impostos, passando a ser obrigadas a cumprir sua função social, preferencialmente por meio de bolsas de estudo.

A oferta de bolsas esteve assim representada desde a sua criação até 2017 (PORTAL PROUNI, 2020), observa-se que os dados de 2018 e 2019 apresentam-se disponibilizados, mas a totalização dos dados está dificultada pela forma de exposição dos relatórios. Estes relatórios foram atualizados a última vez em 20 de janeiro de 2020:

\begin{tabular}{|c|c|c|c|c|c|}
\hline \multirow[t]{3}{*}{ ANO } & \multicolumn{5}{|c|}{ NÚMERO DE BOLSAS } \\
\hline & \multicolumn{2}{|l|}{ INTEGRAL } & \multicolumn{2}{|l|}{ PARCIAL } & \multirow[t]{2}{*}{ TOTAL } \\
\hline & 1ㅇs. sem. & 20 sem. & 10 sem. & 20 sem. & \\
\hline 2005 & - & 71.905 & - & 40.370 & 112.275 \\
\hline 2006 & 63.536 & 35.162 & 28.073 & 11.897 & 138.668 \\
\hline 2007 & 65.276 & 32.355 & 43.366 & 22.857 & 163.854 \\
\hline 2008 & 52.977 & 46.518 & 53.157 & 72.353 & 225.005 \\
\hline 2009 & 95.694 & 57.432 & 60.722 & 33.795 & 247.643 \\
\hline 2010 & 85.208 & 39.882 & 79.388 & 35.963 & 240.441 \\
\hline 2011 & 82.702 & 46.970 & 79.789 & 45.137 & 254.598 \\
\hline 2012 & 98.383 & 52.487 & 95.928 & 37.824 & 284.622 \\
\hline 2013 & 108.686 & 55.693 & 53.643 & 34.352 & 252.374 \\
\hline 2014 & 131.636 & 73.601 & 59.989 & 41.500 & 306.726 \\
\hline 2015 & 135.616 & 68.971 & 77.497 & 47.033 & 329.117 \\
\hline 2016 & 109.462 & 57.141 & 94.140 & 68.437 & 329.180 \\
\hline 2017 & 103.719 & 67.922 & 110.391 & 79.893 & 361.925 \\
\hline Total Global & 1.132 .895 & 706.039 & 836.083 & 571.411 & 3.246 .428 \\
\hline
\end{tabular}

Importante que o programa possui também ações conjuntas de incentivo à permanência dos estudantes nas instituições, como a Bolsa Permanência e ainda o Fundo de Financiamento Estudantil - FIES, que possibilita financiar parte da mensalidade não coberta pela bolsa do programa.

O Programa Universidade para Todos, somado ao Fies, ao Sistema de Seleção Unificada (SISU), ao Programa de Apoio a Planos de Reestruturação e Expansão das Universidades Federais (Reuni), a Universidade Aberta do Brasil (UAB) e a expansão da rede federal de educação profissional e tecnológica ampliam significativamente o número de vagas na educação superior, contribuindo para um maior acesso dos jovens à educação superior (PORTAL PROUNI). 


\section{FUNDO DE FINANCIAMENTO AO ESTUDANTE DO ENSINO SUPERIOR}

O Fundo de Financiamento ao Estudante do Ensino Superior (FIES) é um programa do Ministério da Educação destinado a financiar a graduação na educação superior de estudantes matriculados em instituições não gratuitas. Podem recorrer ao financiamento os estudantes matriculados em cursos superiores que tenham avaliação positiva nos processos conduzidos pelo Ministério da Educação.

O programa foi criado em 1999 durante o governo Fernando Henrique Cardoso e ampliado no governo seguinte de Luís Inácio Lula da Silva, sendo sucessor do Crédito Educativo, criado em 1976 pelo regime militar. A Lei n 11.552, de 19 de novembro de 2007 (BRASIL, 2007b), altera a Lei no 10.260, de 12 de julho de 2001, que dispõe sobre o Fundo de Financiamento ao Estudante do Ensino Superior - Fies.

Além destas três políticas públicas de educação pode-se, ainda, destacar, entre outras, como políticas que visam concretizar o direito à educação e confirmar a efetivação do prescrito na constituição: a) Educação para Jovens e Adultos (EJA) que é um programa que se dedica a educação de jovens e adultos que não concluíram os estudos na idade correta. Este programa atende o ensino fundamental e médio; b) Programa que visa contribuir com a melhora e aumento da frota de veículos que fazem o transporte escolar nas redes de ensino estaduais e municipais; c) Educação nas prisões para garantir um programa educativo de apoio a jovens e adultos que cumprem pena no sistema prisional; d) Programa de educação profissionalizante dirigido aos jovens matriculados no ensino médio da rede pública de ensino.

\section{CONSIDERAÇÕES FINAIS}

A Educação por ser o direito que contribui para o crescimento intelectual, social e cultural do indivíduo, foi alçada ao nível de norma constitucional. Sua importância é de tamanha relevância que a Constituição da República Federativa do Brasil de 1988 caracterizoua como um direito social e apresenta uma seção específica dos artigos 205 ao 214, além de relacioná-la entre os Direitos sociais previstos no artigo 6ㅇ.

Observa-se que a Educação é um dever compartilhado entre Estado, família e Sociedade, contudo, dada a complexidade da efetivação deste direito, é o Estado a organização dotada de poder e autoridade para agir em defesa da Educação.

A CRFB/1988 assume o compromisso de prover o dever do Estado com a Educação, não obstante, assegura os meios para a efetivação deste direito, tanto no âmbito de custeio financeiro quanto de garantias de aplicabilidade da norma.

A Educação ao ser evidenciada como Direito Social e elencada no rol dos Direitos Fundamentais, tornou-se um direito tão importante e relevante quanto o direito à vida, à 
liberdade, à igualdade e tantos outros Direitos Fundamentais elencados na norma constitucional. Todavia, não basta que o Direito à Educação seja reconhecido e declarado, é necessárias garantias para efetivá-lo.

Verifica-se que o direito a educação, encontra guarida nas ações do Estado, nos três níveis (união, estado e municípios) através de Políticas Públicas criadas com a intenção de fortalecer esse direito.

Nesta atividade prestacional, com a criação de políticas públicas é que o Estado garante condições mínimas necessárias a uma existência digna. Estas políticas se apresentam como caminhos para concretizar uma sociedade mais justa e digna. Por outro lado, percebe-se que há lacunas aparentes entre a sociedade real e a sociedade imaginada, entre o proposto e o real, entre o direito a educação e a concretização da educação no dia-a-dia das pessoas.

Entende-se também que estas sementes plantadas através das Políticas Públicas já frutificaram em muitas famílias brasileiras e vem demonstrar para toda a sociedade que é possível construir um Brasil com menos miséria, menos desemprego, menos pobreza e menos corrupção e com muito mais oportunidade e dignidade.

Em sendo assim, destaca-se, novamente, que o direito à educação encontra previsão constitucional e deve ser garantido a todos os cidadãos.

\section{REFERÊNCIAS}

BARROSO, Luiz Roberto. Curso de Direito Constitucional Brasileiro. 5 ed. São Paulo: Saraiva, 2015.

BOBBIO, Norberto. Teoria do ordenamento jurídico. Tradução de Maria Celeste C. J. Santos. 6 ed. Brasília: Universidade de Brasília, 1995.

BRASIL. Constituição da República federativa do Brasil de 1988. Brasília: Senado Federal, 2019.

BRASIL. Decreto 5.493 de 18 de julho de 2005b. Regulamenta o disposto na Lei $n^{\circ} 11.096$, de 13 de janeiro de 2005http://www.planalto.gov.br/ccivil_03/_ato2004-

2006/2005/Decreto/D5493.htm. Acesso em 21 fev. 2020.

BRASIL. Lei 11.096 de 13 de janeiro de 2005a. Institui o Programa Universidade para Todos PROUNI, regula a atuação de entidades beneficentes de assistência social no ensino superior; altera a Lei n 10.891, de 9 de julho de 2004, e dá outras providências. Disponível em: http://www.planalto.gov.br/ccivil_03/_ato2004-2006/2005/Lei/L11096.htm. Acesso em 21 fev. 2020.

BRASIL. Lei 11.494 de 20 de junho de 2007a. Regulamenta o Fundo de Manutenção e Desenvolvimento da Educação Básica e de Valorização dos Profissionais da Educação FUNDEB, de que trata o art. 60 do Ato das Disposições Constitucionais Transitórias; altera a 
Lei $n^{\circ}$ 10.195, de 14 de fevereiro de 2001; revoga dispositivos das Leis nos 9.424 , de 24 de dezembro de 1996, 10.880, de 9 de junho de 2004, e 10.845, de 5 de março de 2004; e dá outras providências. Disponível em: http://www.planalto.gov.br/ccivil_03/_ato20072010/2007/lei/l11494.htm. Acesso em 20 fev. 2020.

BRASIL. Lei 11.552 de 19 de novembro de 2007. Altera a Lei n 10.260, de 12 de julho de 2001, que dispõe sobre o Fundo de Financiamento ao Estudante do Ensino Superior - Fies. Disponível em: http://www.planalto.gov.br/ccivil_03/_Ato2007-2010/2007/Lei/L11552.htm. Acesso em 20 fev. 2020.

BRASIL. Lei n 9.3494 de 20 de dezembro de 1996. Lei de Diretrizes e Bases da Educação Nacional, Brasília, 1996. Disponível em http://www.planalto.gov.br/ccivil_03/leis/L9394compilado.htm. Acesso 04 mar. 2020.

DEMARCHI, C.; COELHO, L. C. P. A efetividade do direito fundamental à educação e a função social do estado. Revista Ciências Jurídicas e Sociais UNIPAR. Umuarama. v. 21, n. 2, p. 185199, jul./dez. 2018. Disponível em:

https://revistas.unipar.br/index.php/juridica/article/view/7501. Acesso 06 mar. 2020.

DEMARCHI, Clovis. CIMADON, Elisandra Riffel. O ensino gratuito nos cursos de pós-graduação lato sensu em instituições públicas e o intérprete na aplicação da norma. Revista de Estudos Constitucionais, Hermenêutica e Teoria do Direito (RECHTD) 9(3):327-335, setembrodezembro 2017 . Unisinos

GOULART, Clovis de Souto. Formas e Sistemas de Governo. Porto Alegre/Fpolis: Sérgio Antonio Fabris Editor/CPGD-UFSC, 1995.

HELLER, Hermann. Teoria do Estado. Tradução de Lycurgo Gomes da Motta. São Paulo: Mestre Jou,1968.

KELSEN, Hans. Teoria Pura do Direito. Tradução de João Baptista Machado. 6 ed. São Paulo Martins Fontes, 1998.

KELSEN, Hans. Teoria geral do direito e do Estado. Tradução de Luís Carlos Borges 3 ed. São Paulo: Martins Fontes, 1998.

LIEBL,Helena; DEMARCHI, Clovis. A Efetividade Da Dignidade Da Pessoa Humana Através Dos Direitos Sociais. Revista da ESMESC, v 25, n. 31, p. 85-106. 2018. Disponível em: https://revista.esmesc.org.br/re/article/view/185.

PASOLD, Cesar Luiz. Função Social do Estado Contemporâneo. 4. ed. rev. amp. Itajaí/SC: Univali, 2013.

PORTAL PROUNI. Dados e estatísticas. Disponível em: http://prouniportal.mec.gov.br/dadose-estatisticas. Acesso 10 maio 2020.

SILVA, José Afonso da. Curso de Direito Constitucional Positivo. 25 ed. São Paulo: Malheiros, 2005. 